Research Article

\title{
Optimization of Cryogenic Process Parameters for the Minimization of Surface Residual Stress in Pure Iron Using Taguchi Design
}

\author{
Meng Zheng $\left(\mathbb{D},{ }^{1}\right.$ Jinxing Kong $\mathbb{D}{ }^{2}$, and Yuwen Sun $\mathbb{D}^{1}$ \\ ${ }^{1}$ Key Laboratory for Precision and Non-Traditional Machining Technology of the Ministry of Education, \\ Dalian University of Technology, Dalian 116024, China \\ ${ }^{2}$ Machinery Manufacturing Technology, China Academy of Engineering Physics, Mianyang 621999, China \\ Correspondence should be addressed to Jinxing Kong; kjxmc106@163.com
}

Received 24 April 2021; Revised 19 June 2021; Accepted 13 October 2021; Published 2 November 2021

Academic Editor: Kamal Kumar

Copyright (c) 2021 Meng Zheng et al. This is an open access article distributed under the Creative Commons Attribution License, which permits unrestricted use, distribution, and reproduction in any medium, provided the original work is properly cited.

The plastic deformation produced in the machining process can cause residual stress. As an effective way to control the residual stresses, the cryogenic process is used in modern industries such as aerospace, automobile, and shipping industry. Focusing on the minimization of surface stress in the cryogenic process of pure iron, the Taguchi design is used in this paper. The effect of cryogenic temperature $(77-193 \mathrm{~K})$, holding time $(8-24 \mathrm{H})$, cooling rate $(2-6 \mathrm{~K} / \mathrm{min})$, and warming-up rate $(0.5-1.5 \mathrm{~K} / \mathrm{min})$ on surface residual stress is discussed and the optimal combination of cryogenic parameters is obtained using signal-to-noise (S/N) ratios. To overcome the weakness of the Taguchi method that cannot calculate stresses, an exponential model to predict residual stresses considering cryogenic parameters is developed. The coefficients of this mathematical model are obtained using multilinear regressive analysis based on the database of the Taguchi experiment. After this, the optimization process is conducted with this model using the genetic algorithm (GA). The optimized results using both ways coincide with each other. The optimal cryogenic parameters are obtained, i.e., cryogenic temperature of $193 \mathrm{~K}$, holding time of $24 \mathrm{~h}$, cooling rate of $2 \mathrm{~K} / \mathrm{min}$, and warming-up rate of $0.5 \mathrm{~K} / \mathrm{min}$. When the optimum cryogenic parameters are used, the surface residual stress is reduced by $42.9 \%$ in the cutting direction and $46.2 \%$ in the feeding direction. The method can be applied to the actual machining engineering to realize the lowstress control on the cutting surface.

\section{Introduction}

The stress, which retains in part even after the external loads are removed, is defined as residual stress $[1,2]$. Compared with compressive stress, tensile stress is undesirable due to its negative effects on the machining dimension and fatigue life, etc. $[2,3]$. Especially for pure iron, as a typical difficultto-cut material, large tensile residual stress is inevitably generated on the surface of the workpiece because of its high plasticity [2]. As an effective way to control stresses, the cryogenic process is a reasonable way to treat pure iron. Therefore, the control of cryogenic process parameters becomes essential to get the ministress.

By now, residual stress of the machined surface is mainly controlled by reducing the mechanical-thermal effect in the machining process. This method usually reduces surface stress through reasonable selection and design of tools [4-6], optimization of cutting parameters [1, 7-9], and improvement of lubrication methods [10]. For example, Yen et al. [4] studied the effect of tool edge geometry on the cutting process, contact stress, cutting temperature, and sliding velocity between the tool and chip, and tool geometry is optimized through finite element analysis. Experiments were performed in [1] based on response surface methodology to develop a statistical model of residual stress. The authors analyzed the effect of parameters in the ultrasonic-assisted turning process and their interactions on residual stresses. Results reveal that percentage intensity and feed rate significantly affect the generation of residual stresses. The regression model of residual stress under different lubrication 
modes is established in [10] to realize the optimization of residual stress.

The above researching works make great efforts to investigate residual stresses. However, they did not study material processing techniques before or after machining, such as heat treatment. Heat treatment can effectively eliminate the material internal stress. The postweld heat treatment of P91 steel has a great effect on residual stresses, reducing peak stresses from around $600 \mathrm{MPa}$ to $20 \mathrm{MPa}$ [11]. It is found in [12] that the heat treatment temperature has the greatest effect on the reduction of residual stresses and distortion compared with the holding time and cooling rate. Additionally, the postswaging annealing of Ti-6Al-4V alloy at $400^{\circ} \mathrm{C}$ can just relieve $80 \%$ of the residual stress, while a higher temperature at $500^{\circ} \mathrm{C}$ can relieve $97 \%$ of the residual stress to achieve the almost stress-free state [13]. However, the heat treatment can make the grain coarsening and the carbide solid solution supersaturation of the material. Moreover, the retained residual stress after heat treatment may reduce the fatigue strength and other mechanical properties of the material, which will easily lead to the deformation of the workpiece in the stress release process.

As a new material treatment technology, the cryogenic process can effectively diminish deficiencies of heat treatment. It can eliminate the internal residual stress, refine the grain structure, improve the wear resistance, and ensure the dimensional stability of the workpiece, which will enhance the machining accuracy and service life of the workpiece [14]. Hence it is wildly used in manufacturing, automotive, aerospace, and medical treatment [15]. Li et al. [16] found that cryogenic laser peening can significantly induce a higher density of dislocation and smaller-size grain of the 2024-T351 aluminum alloy compared with room temperature laser peening. Meanwhile, the tensile strength and elongation were simultaneously increased by $9.36 \%$ and $7.10 \%$, respectively. Li et al. [17] found that the wear resistance is improved by lowering the cryogenic temperature and prolonging the holding time through the wear test of M2 steel. The wear resistance became saturated and reached the highest when the cryogenic treatment is $77 \mathrm{~K}$, the holding time is $24 \mathrm{~h}$, and the cooling rate is $2 \mathrm{~K} /$ min. Hariharan et al. [18] found that the AISI D7 steel tool treated by the cryogenic has a Vickers hardness improvement by $2.9 \mathrm{HV}$ greater than that of normal tool hardness. The material removal rate of mild steel workpiece is slightly increased and accuracy in dimensions along surface finish is significantly upgraded while this material is turned by the cryogenically treated tool. Sert and Celik [19] presented that the cryogenic treatment of tungsten carbide cutting tools can cause martensitic transformation. This transformation rate is high with lower cryogenic treatment. Also, the use of cryogenic cycling allows changing the structure of material including recovery of a partially crystalline structure [20]. Bensely et al. [21] found that cryogenic treatment can improve the overall fatigue life of $71 \%$ over conventionally heat-treated En 353 steel. Han et al. [22] found that the brittleness of shale increases at low temperatures. This phenomenon can be attributed to the shrinkage of mineral grains and the freezing of pore water.
Cryogenic treatment is used to reduce the internal stress mainly through changing the atomic lattice constant caused by volume contraction at low temperatures. In the warmingup and tempering process, the diffusion ability of carbon atoms increases and the formation of ultra-fine carbides, thus the residual stress is reduced. The cryogenic process is mainly used in steel to reduce internal stress. Alexandru and Bulancea [23] pointed out that the strain caused by phase transition can change the state of residual stress. Bensely et al. [24] studied the effect of cryogenic treatment on the residual stress distribution of case-carburized En 353 steel. The results showed that cryogenic treatment would produce large compressive stress, and the compressive residual stress would decrease in the tempering process. This phenomenon could be explained as the increased precipitation of fine carbides in specimens subjected to deep cryogenic treatment with tempering. Senthilkumar et al. [25] found that the tensile residual stress is generated during the traditional heat treatment and the high cryogenic temperature $\left(-80^{\circ} \mathrm{C}\right)$ for 4140 steel, while the compressive residual stress is generated under the low cryogenic temperature $\left(-196^{\circ} \mathrm{C}\right)$. Xu et al. [26] found that residual stress is largely reduced by cryogenic treatment for electron-beam-welded Ti-6Al-4V joints. However, the reduction effect of residual stress is no longer obvious when the holding time of cryogenic treatment exceeds $24 \mathrm{H}$. Sachin et al. [27] showed that, compared with MQL and dry environment diamond burnishing, the compressive residual stress strength of 17-4 pH stainless steel is increased by $20 \%$ and $44 \%$, respectively, in cryogenic environments.

The research work on pure iron mainly focuses on the control of tool wear and lubrication, the stability prediction of the machining process, and the control of machininginduced surface residual stress. Kong et al. [28] researched the notch wear mechanism in the turning process of pure iron under different cooling/lubrication conditions and find that the wear rates reached the maximum in wet cutting followed by dry cutting, rapeseed oil lubrication, and minimum quantity lubrication (MQL) condition. Jiang et al. [29] developed a three-dimensional exponential model for cutting forces by taking the nose radius into account and realized the prediction of chatter stability in turning of pure iron analytically. Luo and Sun [2] optimized process parameters for the minimization of surface residual stress based on central composite design turning experiments data. Their works play a tremendous role in the improvement of machining quality for the pure iron component.

As mentioned above, only a few works focus on the machining of pure iron, and none of them is involved in the cryogenic treatment to reduce the surface residual stress. Meanwhile, how to achieve optimal cryogenic process parameters is not well handled yet. Therefore, in this paper, optimization of cryogenic parameters to minimize the surface residual stress in the cryogenic process is proposed. The research route is shown in Figure 1. Focusing on the minimization of surface residual stress in the cryogenic process of pure iron, an efficient optimization method by using the Taguchi design is proposed. Then, the effects of cryogenic parameter variables including cryogenic 


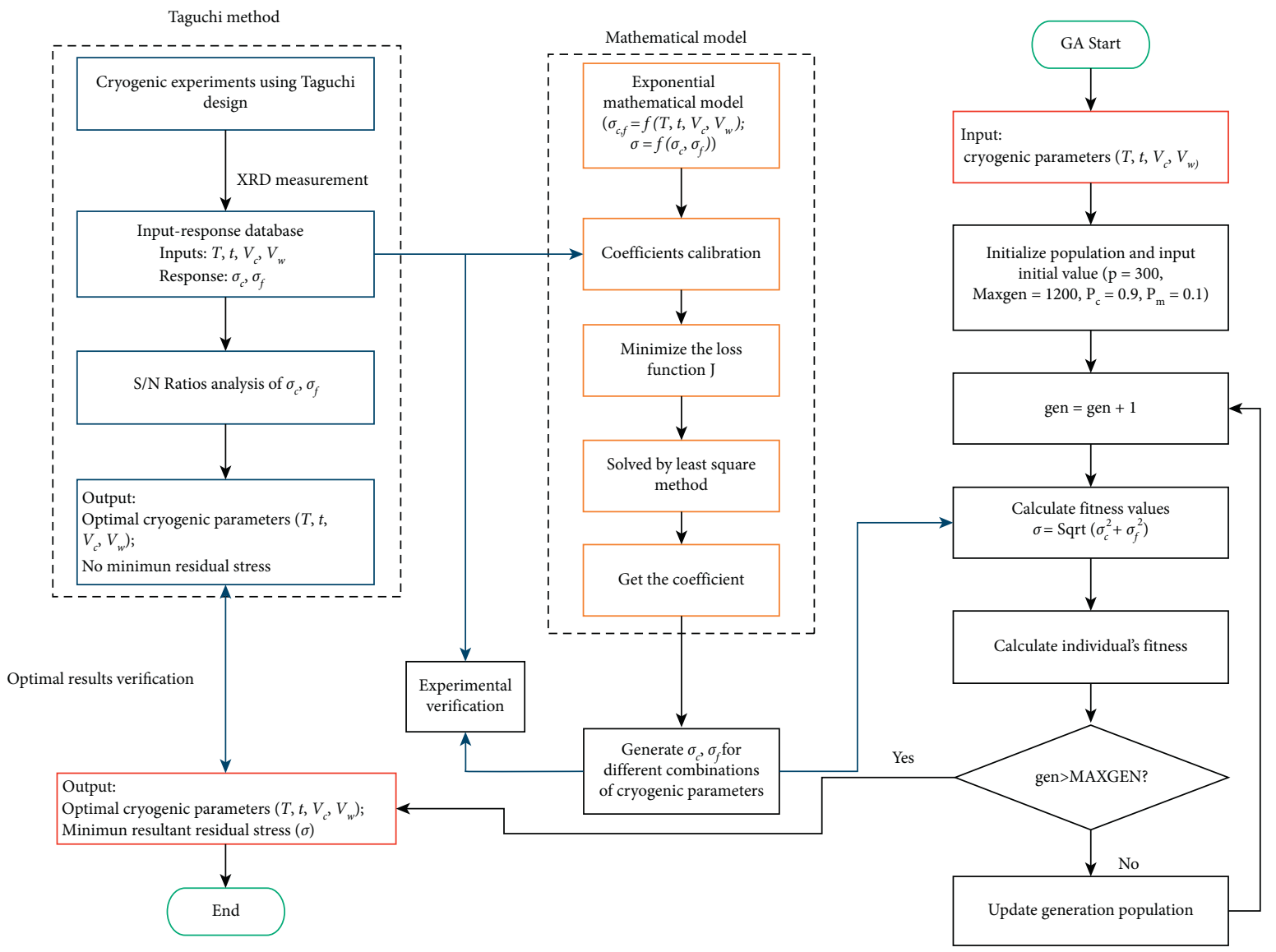

Figure 1: The flowchart of optimization.

temperature, holding time, cooling rate, and warming-up rate on output variables (cutting residual stress and feeding residual stress) are analyzed. Subsequently, the optimized parameters are calculated by means of the main effect plot of $\mathrm{S} / \mathrm{N}$ ratios. To solve the difficulty of the Taguchi method to calculate stresses, an exponential model is proposed to predict residual stresses and then a genetic algorithm (GA) is used for the optimization procedure. The structure of this paper is designed as follows. The method applied for the minimization of surface residual stress is shown in Section 2. Meanwhile, the optimal combination of process parameters is deduced. Section 3 develops a residual stresses prediction modeling. Section 4 investigates the detailed procedures of related residual stress measurements to verify the validity of the proposed model. Section 5 is the conclusion of the paper. It is expected to provide technical support for the control of residual stress on the machined surface of pure iron components.

\section{Methodology of Cryogenic Parameters Optimization}

The process of minimizing surface residual stress is realized using the combination of the cryogenic process parameters based on the following steps:
(1) The design of the Taguchi experimental strategy

(2) Optimization of cryogenic process parameters by Taguchi experiments with $\mathrm{S} / \mathrm{N}$ ratios analysis

2.1. The Design of Taguchi Experiments. The experimental design by orthogonal array can enhance efficiency and saving costs. So it is applied to design the cryogenic experiment. In this paper, the surface residual stresses $\left(\sigma_{c}, \sigma_{f}\right)$ in the cutting and feeding direction are taken as the response characteristics. Input control factors include cryogenic process parameters, i.e., cryogenic temperature $T$, holding time $t$, cooling rate $V_{c}$, and warming-up rate $V_{w}$. The selected levels of the control factors are listed in Table 1.

Based on the Taguchi method, total degrees of freedom $C$ can be calculated using the formula

$$
C=m(T)+m(t)+m\left(V_{c}\right)+m\left(V_{w}\right)-4,
$$

where $m$ stands for the number of levels for each control factor. Here, this value for all the factors is 3 . Then, the number of experiment groups equals total degrees plus 1 , that is, 9. Therefore, Taguchi L9 orthogonal array is used to conduct the cryogenic treatment experiments, which is shown in Table 2. The loss function is defined using the 
TABLE 1: Levels of the control factors.

\begin{tabular}{lccc}
\hline Control factors & Level 1 & Level 2 & Level 3 \\
\hline$T(\mathrm{~K})$ & 193 & 135 & 77 \\
$t(\mathrm{H})$ & 8 & 16 & 24 \\
$V_{c}(\mathrm{~K} / \mathrm{min})$ & 2 & 4 & 6 \\
$V_{w}(\mathrm{~K} / \mathrm{min})$ & 1.5 & 1 & 0.5 \\
\hline
\end{tabular}

TABLE 2: L9 experimental program.

\begin{tabular}{lcccc}
\hline Exp. no. & $T$ & $t$ & $V_{c}$ & $V_{w}$ \\
\hline 1 & 193 & 8 & 2 & 1.5 \\
2 & 193 & 16 & 4 & 1.0 \\
3 & 193 & 24 & 6 & 0.5 \\
4 & 135 & 8 & 4 & 0.5 \\
5 & 135 & 16 & 6 & 1.5 \\
6 & 135 & 24 & 2 & 1.0 \\
7 & 77 & 8 & 6 & 1.0 \\
8 & 77 & 16 & 2 & 0.5 \\
9 & 77 & 24 & 4 & 1.5 \\
\hline
\end{tabular}

relationship between real and ideal values of the residual stresses.

$$
L\left(\sigma_{x}\right)=K \sigma_{x}^{2}, \quad x=c \text { or } f,
$$

where $L\left(\sigma_{x}\right)$ is the actual stress quality characteristics and $K$ is the loss coefficient.

$$
\frac{S}{N}=-10 \log \left(\sum_{i=1}^{n}\left(\frac{L\left(\sigma_{x i}\right)}{K}\right)^{2}\right), \quad x=c \text { or } f .
$$

When the loss function is obtained, the next step is to calculate the values of signal-to-noise $(\mathrm{S} / \mathrm{N})$ ratios. The signal can be expressed as the mean of the measured stresses, and the standard deviation is the noise. To get the minimization of the stress, the following $\mathrm{S} / \mathrm{N}$ formula is used:

In this formula, $n$ is the total number of experiments and $i$ is the $i^{\text {th }}$ experiment in Table 2 . The optimized parameters can be obtained using the maximum value of $\mathrm{S} / \mathrm{N}$.

2.2. Optimization of Cryogenic Parameters. Based on the design of the experiment in the above subsection, cryogenic parameters can be optimized using the $\mathrm{S} / \mathrm{N}$ ratios. Residual stresses of the machined surface are measured using a Pulstec $\mu$-X360s X-ray residual stress analyzer shown in Figure 2.

The measured residual stress results and calculated $\mathrm{S} / \mathrm{N}$ ratios are obtained in Table 3. From this table, it can be seen that the surface residual stresses along the cutting and feeding directions are tensile. Furthermore, the residual stress along the cutting direction is higher than that along the other direction. The maximum and minimum cutting residual stresses are $563 \mathrm{MPa}$ and $352 \mathrm{MPa}$. For the other direction, these two values are $299 \mathrm{MPa}$ and $194 \mathrm{MPa}$, respectively. Another phenomenon can be found that control factors of the cryogenic process in Table 1 influence residual stress significantly. Therefore, the optimization process is introduced here to get the minimization of the stresses.
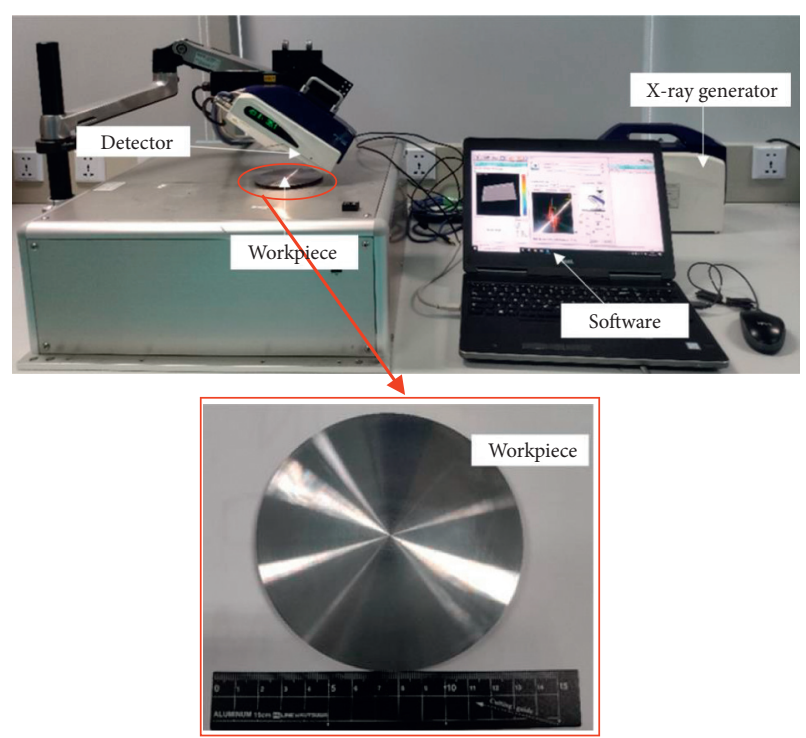

FIGURE 2: Residual stress measurement using $\mu$-X360s equipment.

TABLE 3: L9 experimental program.

\begin{tabular}{lcccc}
\hline Exp. no. & $\sigma_{c}$ & $\sigma_{f}$ & $\mathrm{~S} / \mathrm{N}\left(\sigma_{c}\right)$ & $\mathrm{S} / \mathrm{N}\left(\sigma_{f}\right)$ \\
\hline 1 & 431 & 230 & -52.6895 & -47.2346 \\
2 & 399 & 195 & -52.0195 & -45.8007 \\
3 & 352 & 194 & -50.9309 & -45.756 \\
4 & 517 & 272 & -54.2698 & -48.7126 \\
5 & 509 & 239 & -54.1344 & -47.568 \\
6 & 420 & 220 & -52.465 & -46.8485 \\
7 & 563 & 299 & -55.0102 & -49.5134 \\
8 & 510 & 242 & -54.1514 & -47.6763 \\
9 & 462 & 249 & -53.2928 & -47.924 \\
\hline
\end{tabular}

Figure 3 shows the main effects plot for cutting residual stress and feeding residual stress using the data of the Taguchi experiment. In this figure, the temperature affects stresses most effectively compared with the other three parameters. The next one is cryogenic time. The other two parameters influence stresses relatively small. The residual stresses are reduced with increasing cryogenic temperature and holding time. However, with the increase of cooling rate and warming-up rate, the residual stresses show a reverse trend.

To get the minimum stresses, the maximum values of $\mathrm{S} / \mathrm{N}$ are chosen as the green circles in Figure 3. That means, along the cutting and feeding directions, the optimized parameters are

$$
\left\{\begin{array}{l}
T=193 \mathrm{~K} \\
t=24 \mathrm{H} \\
V_{c}=2 \mathrm{~K} / \mathrm{min} \\
V_{w}=0.5 \mathrm{~K} / \mathrm{min}
\end{array}\right.
$$

Through the above analysis, optimal cryogenic parameters can be finely obtained. However, it is unable to obtain the concrete magnitude of the residual stresses by using this method. Although more experiments can be conducted to investigate the residual stresses under different combinations of cryogenic process parameters, it is costly and timeconsuming. Therefore, in the next section, a new model is 


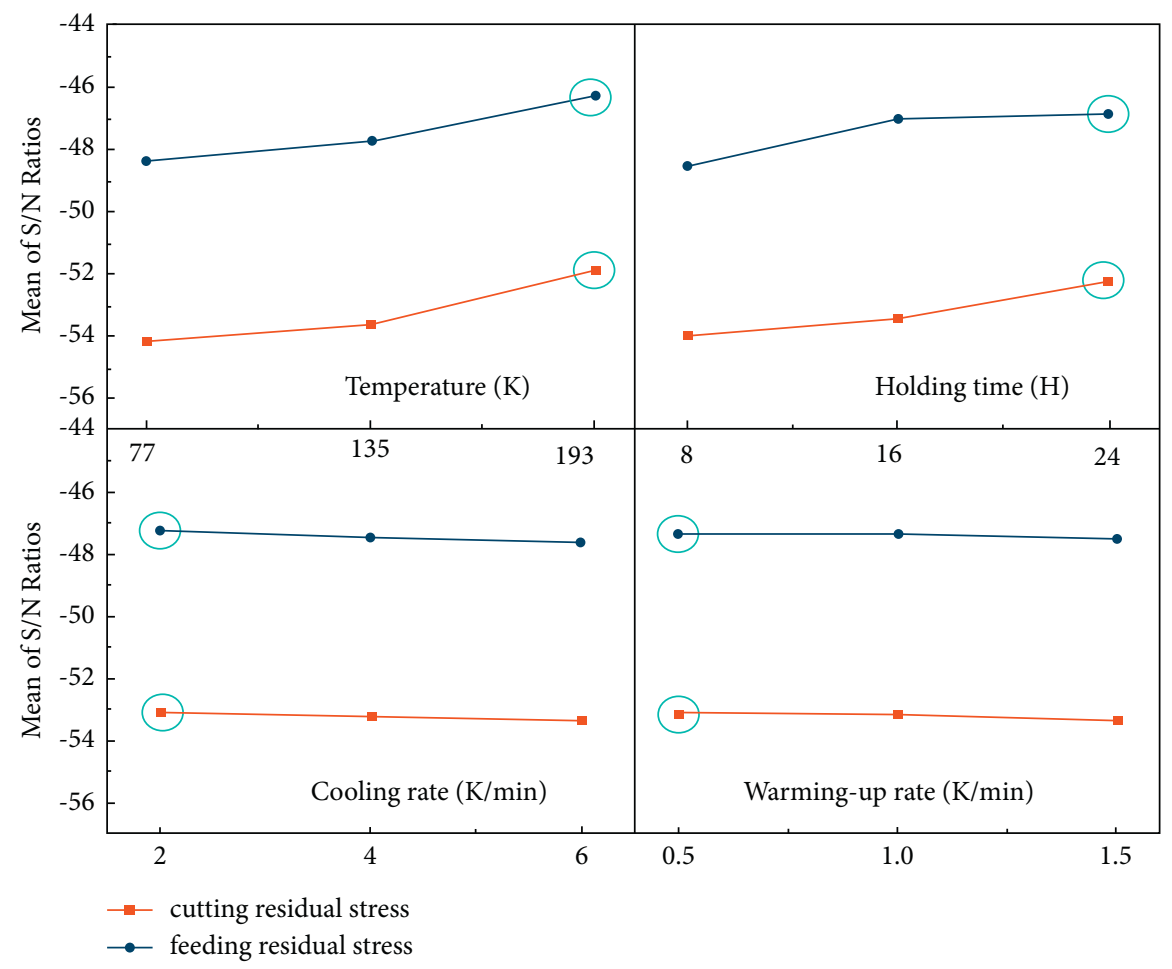

Figure 3: Main effect plot of $\mathrm{S} / \mathrm{N}$ ratios.

constructed to predict the residual stress of pure iron under different cryogenic process parameters.

\section{Residual Stresses Modeling}

3.1. Exponential Model of Surface Residual Stress. Using the four parameters mentioned in the above section, a mathematical model is induced using

$$
\left\{\begin{array}{l}
\sigma_{c}=F_{c} c_{c} T^{k_{c}} t^{l_{c}} V_{c}^{m_{c}} V_{w}^{n_{c}}, \\
\sigma_{f}=F_{f} c_{f} T^{k_{f}} t^{l_{f}} V_{c}^{m_{f}} V_{w}^{n_{f}}, \\
\sigma=\sqrt{\left(\sigma_{c}\right)^{2}+\left(\sigma_{f}\right)^{2}},
\end{array}\right.
$$

where $\sigma$ is the resultant stress, $F_{c}$ and $F_{f}$ are the correction coefficient, $c_{c}$ and $c_{f}$ are the residual stress constant, and $k_{c}$, $l_{c}, m_{c}, n_{c}, k_{f}, l_{f}, m_{f}, n_{f}$ are exponent constants.

To obtain these coefficients, equation (5) is changed into another form:

$$
\left\{\begin{array}{l}
\ln \sigma_{c}=\ln c_{c}+k_{c} T+l_{c} t+m_{c} V_{c}+n_{c} V_{w}, \\
\ln \sigma_{f}=\ln c_{f}+k_{f} T+l_{f} t+m_{f} V_{c}+n_{f} V_{w} .
\end{array}\right.
$$

Then, the mean square error as a loss function is defined as

$$
\begin{aligned}
& J\left(\ln c_{x}, k_{x}, l_{x}, m_{x}, n_{x}\right) \\
& =\frac{1}{M} \sum_{i=1}^{M}\left(\ln \sigma_{x i}-\left(\ln c_{x}+k_{x} T_{x}+l_{x} t_{x}+m_{x} V_{x i}+n_{x} V_{x i}\right)\right)^{2}, \quad x=\operatorname{cor} f,
\end{aligned}
$$

where $M$ is the number of experiments. When the minivalue of equation (7) is obtained, the coefficients in equation (5) can be derived. To realize this, equation (7) is rewritten as the matrix form:

$$
J(\mathbf{C})=(\mathbf{Y}-\mathbf{X C})^{T}(\mathbf{Y}-\mathbf{X C})
$$

We have

$$
\left\{\begin{aligned}
\mathbf{C} & =\left[\begin{array}{lllll}
\ln c_{x} & k_{x} & l_{x} & m_{x} & n_{x}
\end{array}\right]^{T}, \quad x=c \text { or } f \\
\mathbf{X} & =\left[\begin{array}{ccccc}
1 & T_{1} & t_{1} & V_{c 1} & V_{w 1} \\
1 & T_{2} & t_{2} & V_{c 2} & V_{w 2} \\
\vdots & \vdots & \vdots & \vdots & \vdots \\
1 & T_{N} & t_{N} & V_{c N} & V_{w M}
\end{array}\right], \\
\mathbf{Y} & =\left[\begin{array}{lllll}
Y_{0} & Y_{1} & Y_{2} & \ldots & Y_{M}
\end{array}\right]^{T} .
\end{aligned}\right.
$$


Therefore, coefficients can be calculated using the partial derivative which is set to zero.

$$
\frac{\partial J}{\partial c_{x}}=0, \quad x=c \text { or } f \text {. }
$$

Finally, coefficients vector $\mathbf{C}$ is solved using the following equation:

$$
\mathbf{C}=\left(\mathbf{X}^{T} \mathbf{X}\right)^{-1} \mathbf{X}^{T} \mathbf{Y}
$$

Using the experimental results listed in Table 3, the coefficients are calculated and the results are

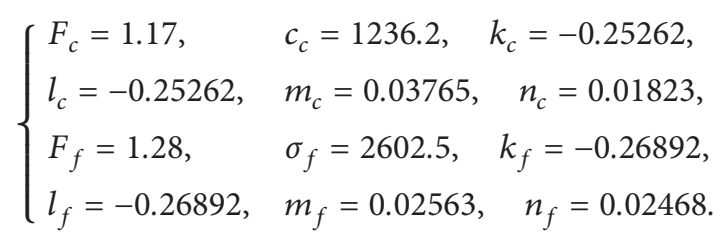

Analysis of variance (ANOVA) is employed to determine the adequacy of residual stress models and the degree of correlation among model terms. The $\mathrm{F}$ test is used to determine the significance test. The level of confidence equals 95\%. The adequacy of the model is checked by correlation coefficient "Adj. R-Squared." The results of ANOVA for the cutting residual stress regression model are shown in Table 4. For the developed exponential model, regression is not significant since $P$ value is more than 0.05 . However, the $P$ value which equals 0.06419 is very close to 0.05. The "Adj. R-Squared" of the proposed model is 0.69111. It can verify the predictive ability of the model. The results of ANOVA for the feeding residual stress regression model are shown in Table 5. For the developed model, regression is significant since $P$-value (0.02596) is less than 0.05 . The "Adj. R-Squared" for feeding residual stress model is 0.80768 which indicates the good predictive ability and high significance of the model.

Using the presented model, the surface residual stresses for a random combination of cryogenic parameters can be predicted. Figure 4 shows the results calculated using the introduced model in (5). In this figure, single factors are considered. For example, for the up-left image, the temperature is changing. However, the other three parameters are fixed as $t=24 \mathrm{H}, V_{c}=2 \mathrm{~K} / \mathrm{min}$, and $V_{w}=0.5 \mathrm{~K} / \mathrm{min}$. The first phenomenon found in this figure is that the effect of each parameter on the residual stress can be illustrated. For temperature, the higher $T$ is, the lower the stresses are. This shows a similar trend as in Figure 3. For the other three parameters, the same regular as that in Figure 3 can be found.

3.2. Optimization Based on Genetic Algorithm (GA). Furthermore, using this model, the combination of cryogenic parameters can also be optimized. Therefore, this section proposes a way to deal with this issue. The optimization function is set as
TABLE 4: Analysis of variance for cutting residual stress model.

\begin{tabular}{lccc}
\hline Source & Regression & Residual error & Total \\
\hline Df & 4 & 4 & 8 \\
Sum of squares & 0.15185 & 0.02774 & 0.17958 \\
Mean square & 0.03796 & 0.00693 & \\
$F$ value & 5.4748 & & \\
Prob $>F$ & 0.06419 & & \\
Remarks & Not significant & & \\
\hline
\end{tabular}

TABLE 5: Analysis of variance for feeding residual stress model.

\begin{tabular}{lccc}
\hline Source & Regression & Residual error & Total \\
\hline Df & 4 & 4 & 8 \\
Sum of squares & 0.14544 & 0.01547 & 0.16091 \\
Mean square & 0.03636 & 0.00387 & \\
$F$ value & 9.39923 & & \\
Prob $>F$ & 0.02596 & & \\
Remarks & Significant & & \\
\hline
\end{tabular}

$$
\begin{cases}\min & (\sigma)=\min \left(\sqrt{\sigma_{c}^{2}+\sigma_{f}^{2}}\right) \\
\text { s.t. } & \left\{\begin{array}{l}
T_{\min }<T<T_{\max }, \\
t_{\min }<t<t_{\max }, \\
V_{c \min }<V_{c}<V_{c \max }, \\
V_{w \min }<V_{w}<V_{w \max },
\end{array}\right.\end{cases}
$$

where $x_{\min }$ and $x_{\max }, x=T, t, V_{c}$ or $V_{w}$ are the extreme values for each parameter.

The genetic algorithm (GA) is suitable for solving constrained or unconstrained optimization problems and can ensure global optimal solutions with a high probability. Thus, for optimization, the GA method is used to obtain the minimization stress and the corresponding combination of cryogenic parameters. The optimization steps are as follows.

Step 1. Set initial values.

The initial population size of genetic algorithm $P$ is 300 , the maximum genetic generation $\mathrm{MaxGen}=1200$, maximum iteration time span $L=20 \mathrm{~s}$, crossover fraction $P_{c}=0.9$, and mutation rate $P_{m}$ is set to 0.1 . The genetic algebra is set gen $=0$.

Step 2. Binary code the independent variables including cryogenic temperature $T$, cryogenic time $t$, cooling rate $V_{c}$, and the warming-up rate $V_{w}$.

These variables are binary coded based on their ranges, and the initial population is generated randomly. The length of chromosomes is set to 80 . Then the counts gen $=$ gen +1 are performed.

Step 3. Calculating the fitness of individuals in the population.

The robust chromosomes which have a smaller fitness are more likely generated in $(u+1)^{\text {th }}$ generation. Nevertheless, those chromosomes whose fitness is large have less opportunity generated in $(u+1)^{\text {th }}$ generation. 


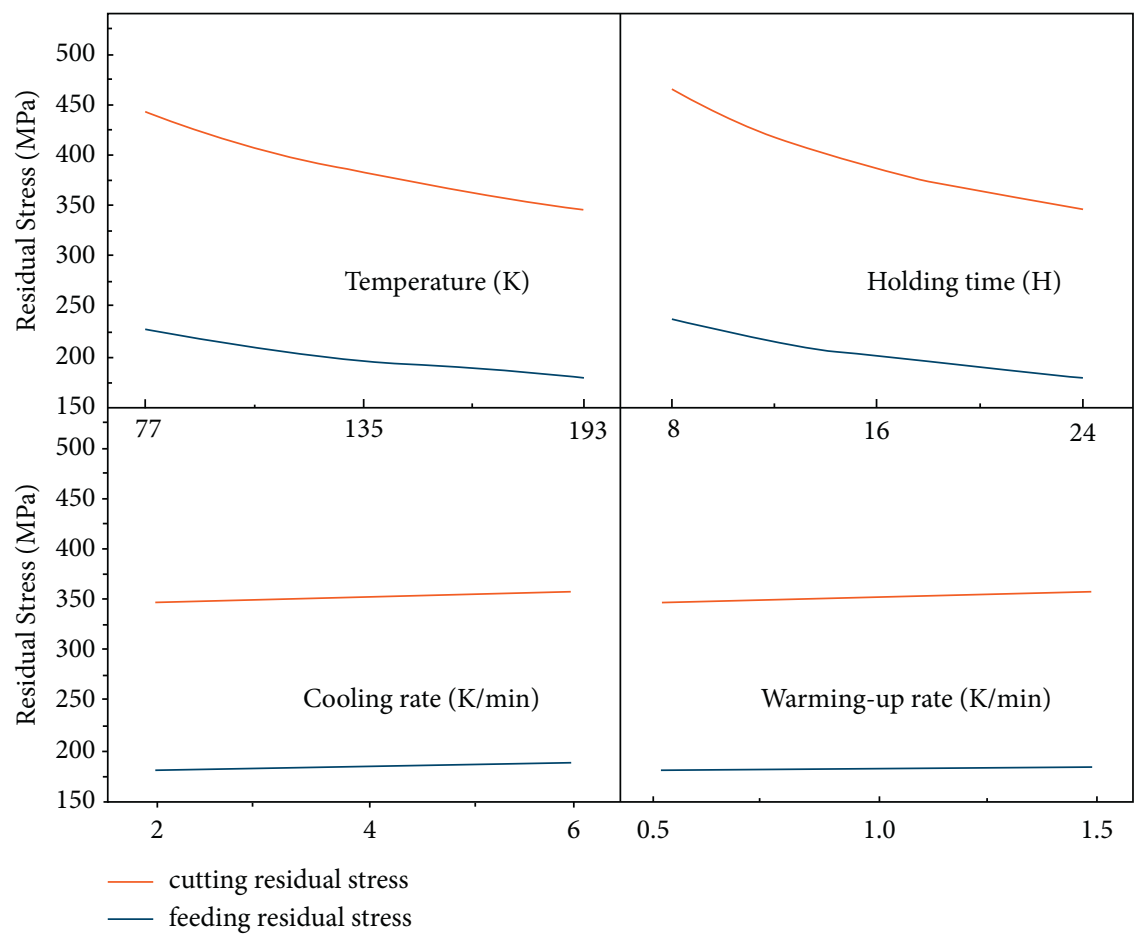

Figure 4: Prediction of the residual stress using the presented model.

Step 4. Crossover operation in the $(u+1)^{\text {th }}$ generation.

According to individual fitness, samples of individuals from the $u^{\text {th }}$ generation are selected and transformed to the $(u+1)^{\text {th }}$ generation for crossover operation.

Step 5. Create new individuals.

A pair of individuals in the group are taken as parents. Using the crossover probability, a single crossover operation is carried out and two new individuals are created.

Step 6. Mutation operation.

Individuals are selected randomly in the population with a certain probability for mutation operation. New individuals are generated by changing some of the individual's genes.

Step 7. Terminate the iterative process.

If gen $\leq$ MaxGen, go to Step 2; if gen $>$ MaxGen or the value of average fitness changes continuously less than a constant over a certain algebra, the obtained individual with maximum adaptation is taken as the optimal solution, and the iterative process can be terminated.

Step 8. Obtain the optimal cryogenic parameters.

Through translation of optimal solution code, the optimal parameters can be found.

As evolution progresses, individuals with low fitness are gradually eliminated. On the other hand, individuals with high fitness can survive in the vicinity of the optimal value. Finally, the optimal values are found. According to the above steps, the cryogenic parameters $T, t, V_{c}$, and $V_{w}$ are optimized. The algorithm is run using the optimization tool in
MATLAB R2014a software. The iterative process is shown in Figure 5.

In this figure, after 310 iterations, the genetic algorithm converges and the target residual stress $\sigma$ is $395 \mathrm{MPa}$, and corresponding cryogenic temperature $T=193 \mathrm{~K}$, cryogenic time $t=24 \mathrm{H}$, cooling rate $V_{c}=2 \mathrm{~K} / \mathrm{min}$, and warming-up rate $V_{w}=0.5 \mathrm{~K} / \mathrm{min}$. This is proved by the Taguchi method.

\section{Results and Discussion}

This section introduces an experimental strategy to measure the surface residual stress. Simultaneously, the correctness of the introduced model can be verified using the experimental database.

4.1. Measurement Strategy. The disc-like DT4E pure iron blanks with a diameter of $120 \mathrm{~mm}$ and an initial thickness of $5.5 \mathrm{~mm}$ are selected for the experiment of cryogenic treatment. The cryogenic treatment is conducted using the equipment named SL-500. The cryogenic equipment uses liquid nitrogen as the cold source which is stored in the liquid nitrogen tank. This liquid flows into the cryogenic box through the transfer pipeline in the working process. This equipment can control temperature, holding time, cooling rate, and warming-up rate automatically through a PCL touch screen. In one cryogenic cycle, the temperature is gradually declined to one of its levels. Then the workpieces are held in this situation for certain durations. Finally, the workpiece is warmed up gradually to room temperature. The temperature deviation is controlled within $\pm 2 \mathrm{~K}$. The range of temperature is from $77 \mathrm{~K}$ to $303 \mathrm{~K}$. 


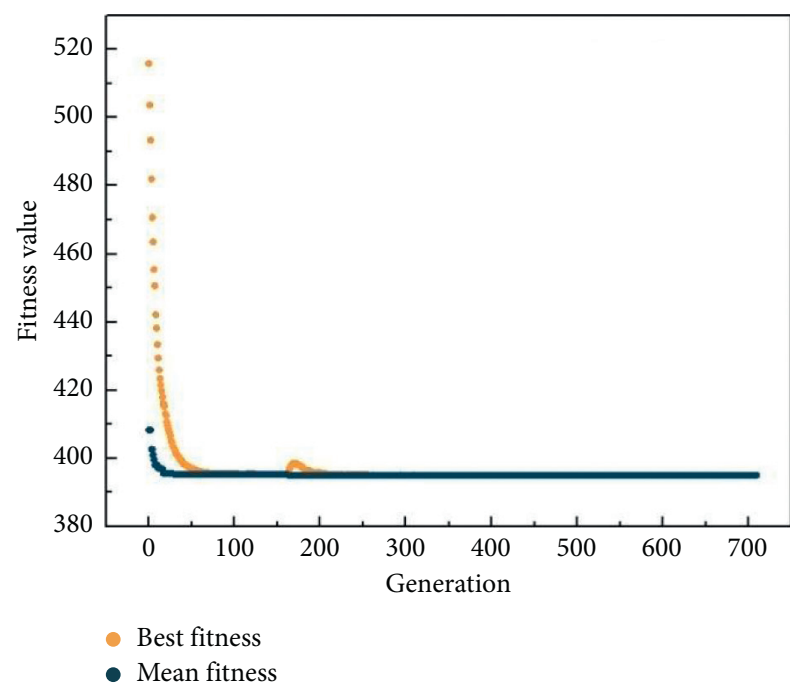

FIGURE 5: Optimization of cryogenic parameters using GA.

To obtain the rational surface, which is suitable to detect residual stress using the $\mu$-X360s X-ray residual stress analyzer, the pure iron is machined by finish turning with the same cutting parameters. The turning process is conducted in a CNC lathe MJ520 with the same cutting parameters and cooling or lubrication conditions. The turning insert DCGT11T302-HP mounted in an SDJCL2525M11 righthand tool holder is used for the machining of pure iron. The chemical compositions of pure iron blanks are illustrated in Table 6 and the cutting parameters are listed in Table 7. Then, the samples are put on the mobile platform of the X-ray residual stress analyzer for measurement. The residual stress of each workpiece is measured four times and the average value is taken. The obtained data are shown in Figure 6.

The Debye ring at the given point on the sample surface is measured as shown in Figure 6(a). Based on this ring, the Debye profile in the range of 360 degrees can be gained. The plot between the strain and $\cos (\alpha)$ in Figure 6(c) is also derived. Based on these pieces of information, the relationship between diffraction angle vs. $a$ can be calculated, which is shown in Figure 6(e). The half-value is calculated using the Debye profile. At the same time, full width at half maxima (FWHM) is computed. In the last image, the peak strength is evaluated. Finally, the calculation of residual stress uses the cosine $a$ method. Measuring conditions are shown in Table 8.

Electron backscatter diffraction (EBSD) is performed to determine the texture orientation of the optimal cryogenically treated sample and without cryogenically treated sample. It is equipped with a Nordlys II Nano EBSD camera (maximum resolution: $1344 \times 1024$ pixels) from Oxford Instruments. The samples are vibration polished and argon ion polished to fully remove the surface stress layer after standard metallographic polishing is completed. The inclination angle $70^{\circ}$, working distance $15 \mathrm{~mm}$, high voltage $20 \mathrm{KV}$, and beam current approximately $10 \mathrm{nA}$ are used during data collection. The EBSD data is processed using HKL Technologies Channel 5 software for orientation analysis.
TABle 6: The chemical composition of pure iron blanks.

\begin{tabular}{lc}
\hline Element & $W_{t} \%$ \\
\hline $\mathrm{Fe}$ & $>99.8$ \\
$\mathrm{C}$ & 0.013 \\
$\mathrm{Si}$ & 0.028 \\
$\mathrm{Mn}$ & 0.029 \\
$\mathrm{Ni}$ & 0.035 \\
$\mathrm{~S}$ & 0.02 \\
$\mathrm{Cr}$ & 0.02 \\
$\mathrm{Cu}$ & 0.034 \\
$\mathrm{P}$ & 0.0072 \\
$\mathrm{Al}$ & 0.0023 \\
\hline
\end{tabular}

TABLE 7: The cutting parameters.

\begin{tabular}{lc}
\hline Parameters & Value \\
\hline Cutting speed V $(\mathrm{m} / \mathrm{min})$ & 200 \\
Depth of cut ap $(\mathrm{mm})$ & 0.05 \\
Feed $f(\mathrm{~mm} / \mathrm{rev})$ & 0.12 \\
\hline
\end{tabular}

4.2. Model Verification. To verify the model in (5), the predicted values of stress with different parameters are compared with that in the experiment. The comparison results are shown in Figure 7. It can be seen that the predicted residual stresses closely agree with the measured ones in both directions. The maximum error of the surface residual stresses is around $11.7 \%$ in the cutting direction and $9.18 \%$ in the feeding direction. Hence, the developed exponent mathematical model can be used to predict the surface residual stress of cryogenically treated pure iron material.

The experiments to verify the validity of the proposed residual stress model are conducted with the optimal cryogenic parameters, which are cryogenic temperature $193 \mathrm{~K}$, cryogenic time $24 \mathrm{H}$, cooling rate $2 \mathrm{~K} / \mathrm{min}$, and temping rate $0.5 \mathrm{~K} / \mathrm{min}$. The surface residual stress is also measured using $\mu$-X360s equipment. The results of verified experiments are shown in Table 9. It can be found that the prediction error of the proposed mathematical model for surface residual stress calculation is less than $5.17 \%$ in the cutting direction and $7.14 \%$ in the feeding direction. Therefore, the model is of high accuracy.

Meanwhile, to illustrate the advantage of cryogenic treatment on reducing surface residual stress, the residual stress without cryogenic treat is also measured by the XRD. Compared with the results before treatment, the surface residual stress of the treated workpiece using optimal parameters is $329 \mathrm{MPa}$ in the cutting direction and $168 \mathrm{MPa}$ in the feed direction. The amount of reduction from the untreated state is $247 \mathrm{MPa}$ in the cutting direction and $144 \mathrm{MPa}$ in the other direction.

In the cryogenic process, the homogeneously distributed carbides and small-sized particles are formed. These carbide particles lead to an improvement in wear resistance and mechanical properties, such as the increase of the hardness and lifetime, the reduction of wear, and the change of microstructure after cryogenic treatment. This may lead to a 


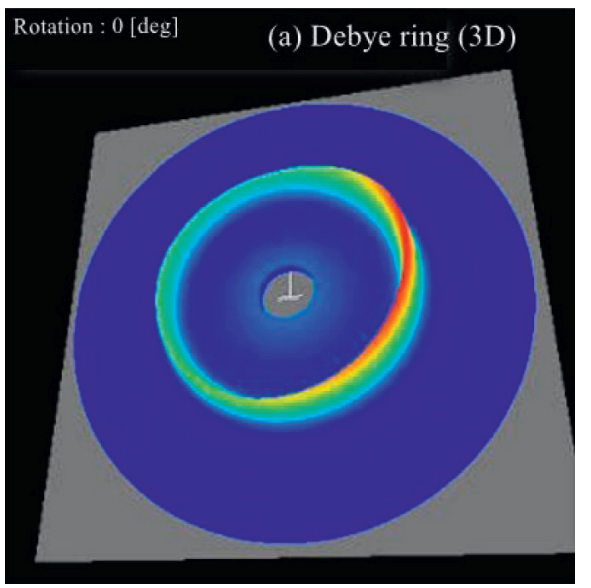

(a)

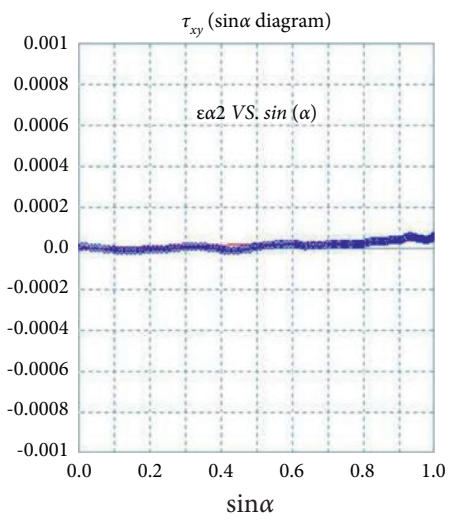

(d)

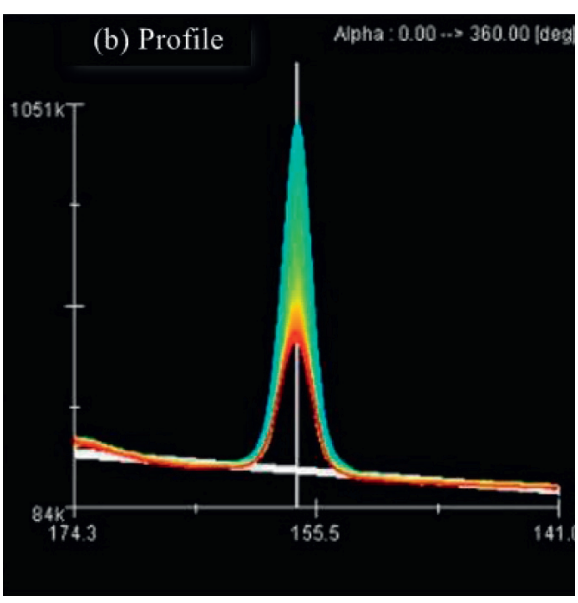

(b)

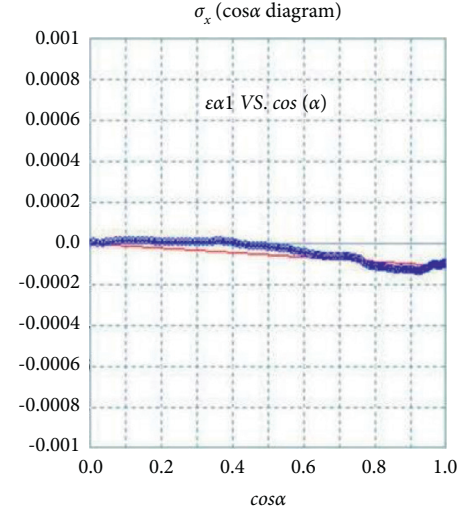

(c)

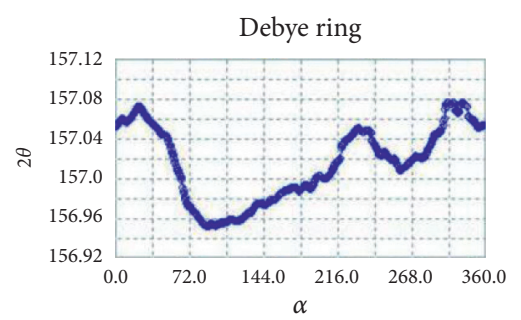

(e)

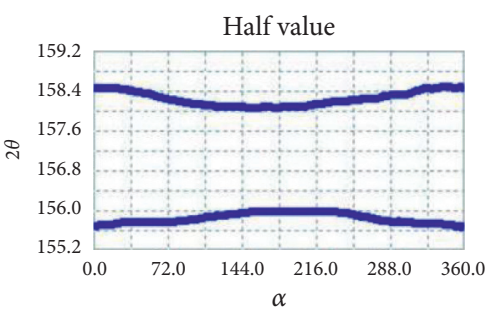

(f)

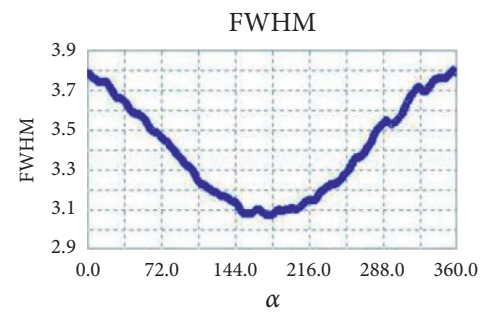

(g)

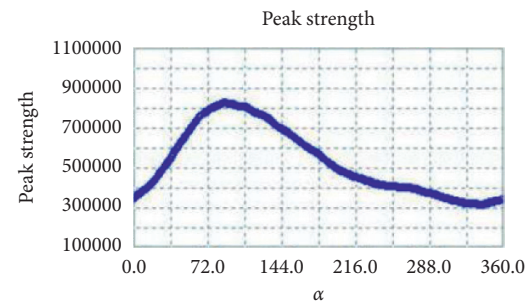

(h)

FIgURE 6: Measured stress result using the X-ray residual stress analyzer. (a) Debye ring (3D). (b) Profile. (c) $\sigma_{x}$ ( $\cos \alpha$ diagram). (d) $\tau_{x y}$ (sin $\alpha$ diagram). (e) Debye ring. (f) Half-value. (g) FWHM. (h) Peak strength.

TABLE 8: Measuring conditions of X-ray equipment.

\begin{tabular}{lc}
\hline Item & Value \\
\hline Characteristics X-ray & $\mathrm{CrK} \alpha$ \\
Diffraction line & 211 \\
Crystal structure & B.C.C \\
Tube voltage $(\mathrm{kV})$ & 30 \\
Tube current $(\mathrm{mA})$ & 0.1 \\
X-ray incident angle, $\psi_{0}(\mathrm{deg})$ & 35 \\
Young's modulus $E(\mathrm{GPa})$ & 224 \\
Poisson's ratio $\nu$ & 0.28 \\
Diffraction angle $2 \theta(\mathrm{deg})$ & 156.396 \\
\hline
\end{tabular}

decrease in the surface tensile residual stress of the pure iron. In the other aspect, the residual stress is reduced mainly through the change of atomic lattice constant caused by volume contraction in the cryogenic environment. In the warming-up process, the diffusion ability of carbon atoms increased. The segregation of carbon atoms from the octahedral or tetrahedral site of ferrite lattice to the defect regions causes more refining grain. And the more stable tissue performance results in the reduction of residual stress. This can be proved by the inverse pole (Figures $8(\mathrm{a})$ and $8(\mathrm{~b})$ ) obtained by electron backscatter diffraction. The microstructure of pure iron shows a (111) 


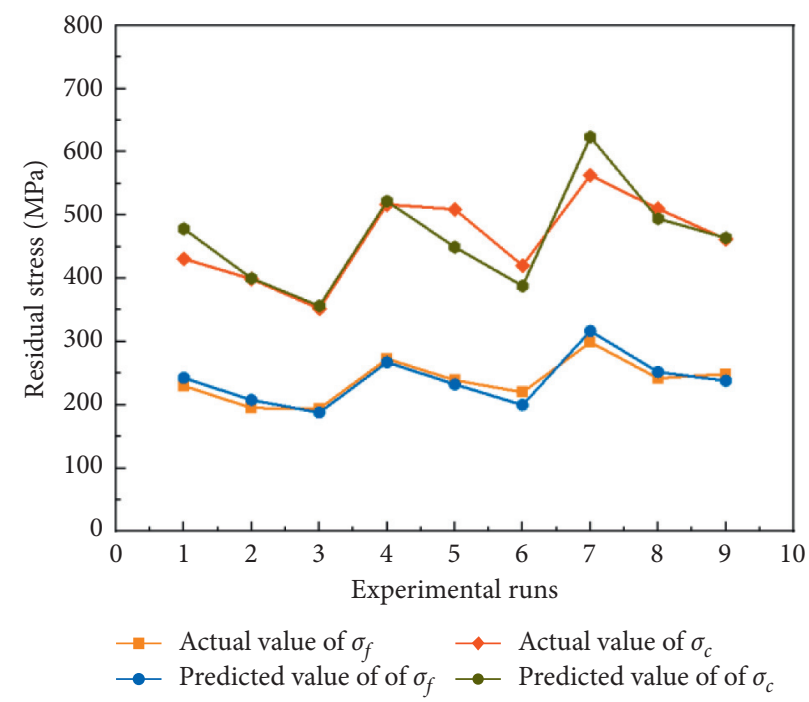

FigURE 7: Actual and predicted values of surface residual stress.

TABLE 9: Results of verification test.

\begin{tabular}{lcc}
\hline Item & $\sigma_{c}(\mathrm{MPa})$ & $\sigma_{f}(\mathrm{MPa})$ \\
\hline Experiment & 329 & 168 \\
Model & 346 & 180 \\
Error & $5.17 \%$ & $7.14 \%$ \\
\hline
\end{tabular}

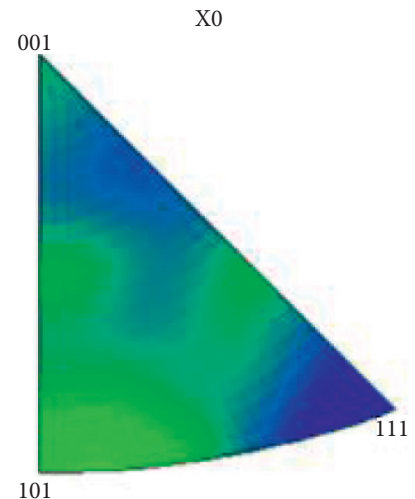

X0

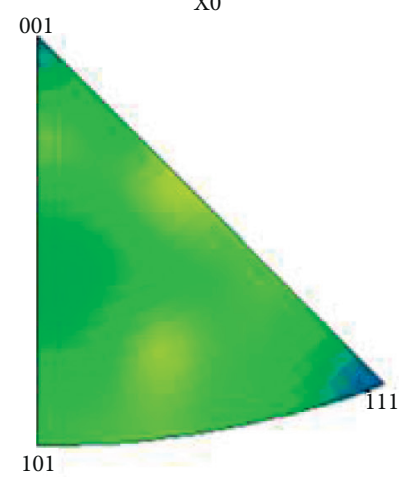

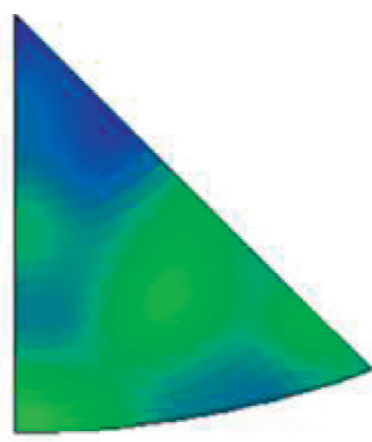

(a)
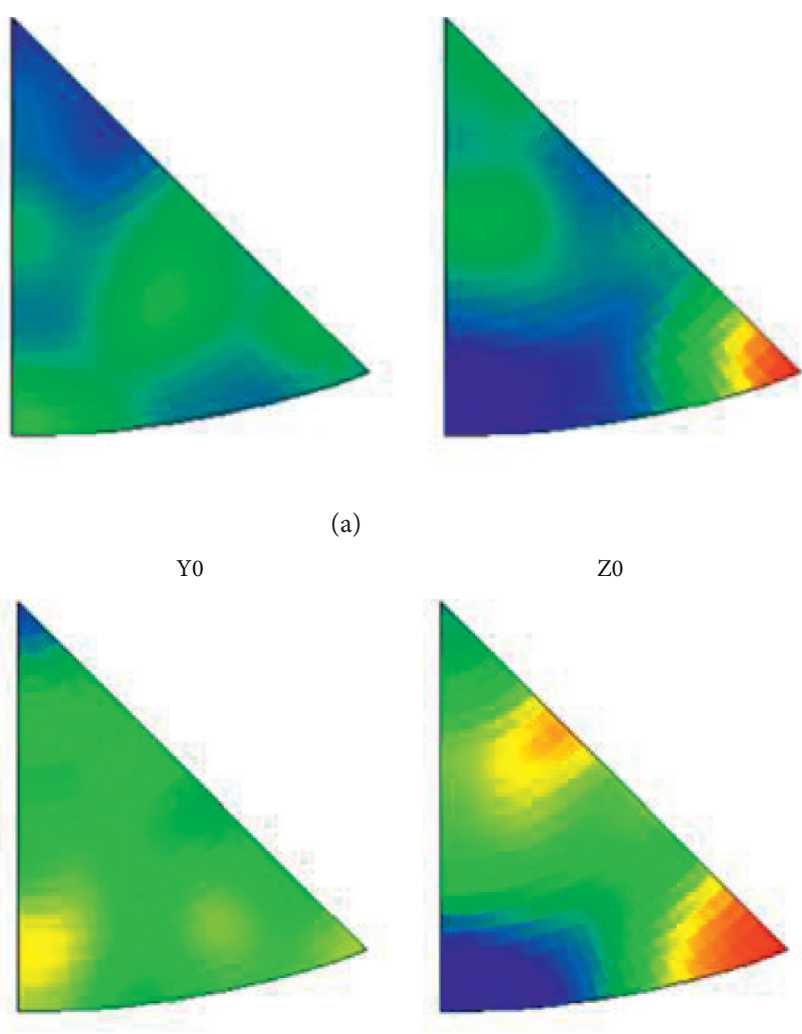

Z0
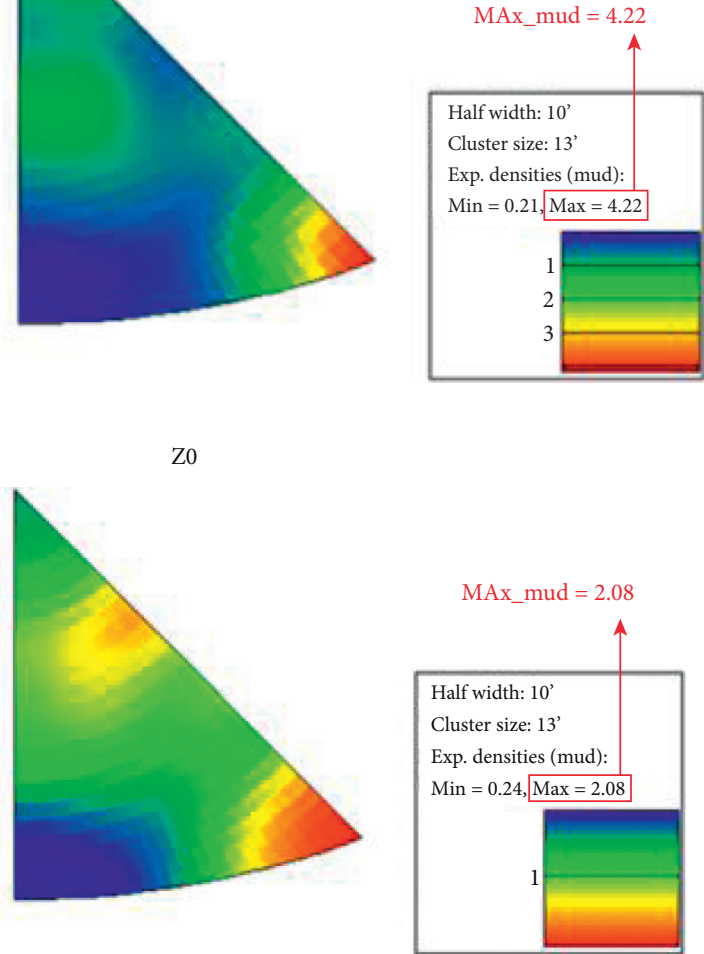

(b)

FIgURE 8: The inverse pole image of pure iron material. (a) Without cryogenic treatment. (b) Optimal cryogenic treatment. 
textural trend. However, using the optimum cryogenic parameter, the texture is improved and maximum extreme density intensity (MUD) is reduced from 4.22 to 2.08 .

\section{Conclusion}

The Taguchi design is introduced to minimize the surface residual stress in the cryogenic process of pure iron. In this process, the influence of cryogenic process parameters on the surface cutting residual stress and feeding residual stress are studied by using the signal-to-noise ratios $(\mathrm{S} / \mathrm{N})$ analysis. Simultaneously, a mathematical model for predicting the residual stress is established based on multiple linear regression analysis to overcome the difficulty of the Taguchi method. The following conclusions can be drawn:

(1) It is found by Taguchi's S/N ratios analysis that, with the increase of cryogenic temperature and holding time, the surface residual stress of cryogenically treated pure iron both in the cutting and feeding directions is all reduced. In contrast, the influences of the other two parameters on stresses show a different trend.

(2) The developed mathematical model is used to calculate the surface residual stress. Compared with the experimental data, the residual stress prediction error is less than $11.7 \%$ in the cutting direction and $9.18 \%$ in the feeding direction, which indicates that the mathematical model established can predict surface residual stress of cryogenically treated pure iron with high accuracy.

(3) Within the given parameter range, the optimal cryogenic parameters for generating minimum surface stress are determined by Taguchi's $\mathrm{S} / \mathrm{N}$ ratios as cryogenic temperature $193 \mathrm{~K}$, cryogenic time $24 \mathrm{H}$, cooling rate $2 \mathrm{~K} / \mathrm{min}$, and temping rate $0.5 \mathrm{~K} / \mathrm{min}$.

(4) The obtained optimal cryogenic parameters by using a genetic algorithm are consistent with the results of Taguchi's S/N ratios analysis for residual stress.

(5) Compared with the no cryogenically treated workpiece, using the obtained optimum parameters for the cryogenic treatment of pure iron, the surface residual stress is reduced by $42.9 \%$ in the cutting direction and $46.2 \%$ in the feeding direction, respectively.

\section{Data Availability}

The data used to support the findings of this study are available within the article or from the corresponding author upon request.

\section{Conflicts of Interest}

The authors declare that they do not have any commercial or associative interest that represents conflicts of interest in connection with the work submitted.

\section{Acknowledgments}

This work was supported by the Science Challenge Project, no. JDZZ2016006-01, and the National Natural Science Foundation of China, no. 51805498.

\section{References}

[1] V. Sharma and P. M. Pandey, "Optimization of machining and vibration parameters for residual stresses minimization in ultrasonic assisted turning of 4340 hardened steel," Ultrasonics, vol. 70, pp. 172-182, 2016.

[2] J. Luo and Y. Sun, "Optimization of process parameters for the minimization of surface residual stress in turning pure iron material using central composite design," Measurement, vol. 163, Article ID 108001, 2020.

[3] N. Masmiati, A. A. D. Sarhan, M. A. N. Hassan, and M. Hamdi, "Optimization of cutting conditions for minimum residual stress, cutting force and surface roughness in end milling of S50C medium carbon steel," Measurement, vol. 86, pp. 253-265, 2016.

[4] Y.-C. Yen, A. Jain, and T. Altan, "A finite element analysis of orthogonal machining using different tool edge geometries," Journal of Materials Processing Technology, vol. 146, no. 1, pp. 72-81, 2004.

[5] X. Cheng, X. Zha, and F. Jiang, "Optimizing the geometric parameters of cutting edge for rough machining $\mathrm{Fe}-\mathrm{Cr}-\mathrm{Ni}$ stainless steel," International Journal of Advanced Manufacturing Technology, vol. 85, no. 1-4, pp. 683-693, 2016.

[6] X. Cheng, S. Jin, T. Liao, and F. Jiang, "Optimizing the geometric parameters of chamfered edge for rough machining Fe-Cr-Ni stainless steel," International Journal of Advanced Manufacturing Technology, vol. 91, no. 1-4, pp. 137-146, 2017.

[7] E. Capello, "Residual stresses in turning," Journal of Materials Processing Technology, vol. 160, no. 2, pp. 221-228, 2005.

[8] S. Saini, I. S. Ahuja, and V. S. Sharma, "Modelling the effects of cutting parameters on residual stresses in hard turning of AISI H11 tool steel," International Journal of Advanced Manufacturing Technology, vol. 65, no. 5-8, pp. 667-678, 2013.

[9] L. Meng, N. He, Y. Yang, and W. Zhao, "Measurement of surface residual stresses generated by turning thin-wall Ti6Al4V tubes using different cutting parameters," Rare Metal Materials \& Engineering, vol. 44, no. 10, pp. 2381-2386, 2015.

[10] T. Leppert and R. L. Peng, "Residual stresses in surface layer after dry and MQL turning of AISI 316L steel," Production Engineering, vol. 6, no. 4-5, pp. 367-374, 2012.

[11] A. H. Yaghi, T. H. Hyde, A. A. Becker et al., "Comparison of measured and modelled residual stresses in a welded P91 steel pipe undergoing post weld heat treatment," International Journal of Pressure Vessels and Piping, vol. 181, Article ID 104076, 2020.

[12] B. Huang, J. Liu, S. Zhang, Q. Chen, and L. Chen, "Effect of post-weld heat treatment on the residual stress and deformation of $20 / 0 \mathrm{Cr} 18 \mathrm{Ni} 9$ dissimilar metal welded joint by experiments and simulations," Journal of Materials Research and Technology, vol. 9, no. 3, pp. 6186-6200, 2020.

[13] L. Yuan, W. Wang, Y. Li, M. Yang, H. Zhang, and W. Zhang, "Effect of annealing temperature on texture and residual stress of Ti-6Al-4V alloy seamless tubing processed by cold rotary swaging," Vacuum, vol. 177, Article ID 109399, 2020. 
[14] T. H. Guan, H. M. Liu, Y. B. Xu, C. Q. Wu, and Y. Lv, "Research status and application prospect of deep cryogenic treatment technology on cemented carbide," Advanced Materials Research, vol. 989-994, pp. 871-875, 2014.

[15] T. Sonar, S. Lomte, and C. Gogte, "Cryogenic treatment of metal-a review," Materials Today: Proceedings, vol. 5, no. 11, pp. 25219-25228, 2018.

[16] J. Li, J. Zhou, A. Feng et al., "Analysis of microstructure and tensile properties produced by cryogenic laser peening on 2024T351 aluminum alloy," Vacuum, vol. 158, pp. 141-145, 2018.

[17] J. Li, X. Yan, X. Liang, H. Guo, and D. Y. Li, "Influence of different cryogenic treatments on high-temperature wear behavior of M2 steel," Wear, vol. 376-377, pp. 1112-1121, 2017.

[18] KB. Hariharan, S. Saravanan, and N. Parkunam, "Life time improvement of D7 tool steel by cryogenic treatment," Materials Today: Proceedings, vol. 21, no. 1, pp. 619-621, 2019.

[19] A. Sert and O. N. Celik, "Characterization of the mechanism of cryogenic treatment on the microstructural changes in tungsten carbide cutting tools," Materials Characterization, vol. 150, pp. 1-7, 2019.

[20] G. Abrosimova, N. Volkov, T. Pershina, and A. Aronin, "Cryogenic rejuvenation of Al-based amorphous-nanocrystalline alloys," Materials Letters, vol. 240, pp. 150-152, 2019.

[21] A. Bensely, L. Shyamala, S. Harish et al., "Fatigue behaviour and fracture mechanism of cryogenically treated En 353 steel," Materials \& Design, vol. 30, no. 8, pp. 2955-2962, 2009.

[22] S. Han, Q. Gao, Y. Cheng, C. Yan, Z. Han, and X. Shi, "Experimental study on brittle response of shale to cryogenic fluid nitrogen treatment," Journal of Petroleum Science and Engineering, vol. 194, Article ID 107463, 2020.

[23] I. Alexandru and V. Bulancea, "Effect of cryogenic cooling on residual stresses, structure and substructure," from: in Handbook of Residual stress and Deformation of Steel, G. Totten, M. Howes, and T. Inoue, Eds., pp. 331-334, ASM International, Ohio, 2002.

[24] A. Bensely, S. Venkatesh, D. M. Lal, G. Nagarajan, A. Rajadurai, and K. Junik, "Effect of cryogenic treatment on distribution of residual stress in case carburized En 353 steel," Materials Science and Engineering A, vol. 479, no. 1-2, pp. 229-235, 2008.

[25] D. Senthilkumar, I. Rajendran, M. Pellizzari, and J. Siiriainen, "Influence of shallow and deep cryogenic treatment on the residual state of stress of 4140 steel," Journal of Materials Processing Technology, vol. 211, no. 3, pp. 396-401, 2011.

[26] L. Y. Xu, J. Zhu, H. Y. Jing, L. Zhao, X. Q. Lv, and Y. D. Han, "Effects of deep cryogenic treatment on the residual stress and mechanical properties of electron-beam-welded Ti-6Al-4V joints," Materials Science and Engineering A, vol. 673, pp. 503-510, 2016.

[27] B. Sachin, S. Narendranath, and D. Chakradhar, "Effect of cryogenic diamond burnishing on residual stress and microhardness of 17-4 ph stainless steel," Materials Today: Proceedings, vol. 5, no. 9, pp. 18393-18399, 2018.

[28] J. Kong, Z. Xia, D. Xu, and N. He, "Investigation on notch wear mechanism in finish turning pure iron material with uncoated carbide tools under different cooling/lubrication conditions," International Journal of Advanced Manufacturing Technology, vol. 86, no. 1-4, pp. 97-105, 2016.

[29] S. Jiang, S. Yan, Y. Liu, C. Duan, J. Xu, and Y. Sun, “Analytical prediction of chatter stability in turning of low-stiffness pure iron parts by nosed tool," International Journal of Advanced Manufacturing Technology, vol. 102, no. 5-8, pp. 1227-1237, 2019. 